Research Article

\title{
Comparing Asset Pricing Factor Models under Multivariate t-Distribution: Evidence from China
}

\author{
Xi Sun $\mathbb{D}^{1},{ }^{1}$ Yihao Chen, ${ }^{1}$ Yulin Chen, ${ }^{1}$ Zhusheng Lou, ${ }^{1}$ Lingfeng Tao $\mathbb{D},{ }^{1}$ and Yihao Zhang ${ }^{2}$ \\ ${ }^{1}$ Hanqing Advanced Institute of Economics and Finance, Renmin University of China, Beijing 100872, China \\ ${ }^{2}$ Business School, Nanjing University, Nanjing 210093, China \\ Correspondence should be addressed to Xi Sun; xi.sun@ruc.edu.cn
}

Received 2 January 2021; Accepted 25 May 2021; Published 3 June 2021

Academic Editor: Junhai Ma

Copyright (C) 2021 Xi Sun et al. This is an open access article distributed under the Creative Commons Attribution License, which permits unrestricted use, distribution, and reproduction in any medium, provided the original work is properly cited.

Factor models provide a cornerstone for understanding financial asset pricing; however, research on China's stock market risk premia is still limited. Motivated by this, this paper proposes a four-factor model for China's stock market that includes a market factor, a size factor, a value factor, and a liquidity factor. We compare our four-factor model with a set of prominent factor models based on newly developed likelihood-ratio tests and Bayesian methods. Along with the comparison, we also find supporting evidence for the alternative $t$-distribution assumption for empirical asset pricing studies. Our results show the following: (1) distributional tests suggest that the returns of factors and stock return anomalies are fat-tailed and therefore are better captured by t-distributions than by normality; (2) under t-distribution assumptions, our four-factor model outperforms a set of prominent factor models in terms of explaining the factors in each other, pricing a comprehensive list of stock return anomalies, and Bayesian marginal likelihoods; (3) model comparison results vary across normality and t-distribution assumptions, which suggests that distributional assumptions matter for asset pricing studies. This paper contributes to the literature by proposing an effective asset pricing factor model and providing factor model comparison tests under non-normal distributional assumptions in the context of China.

\section{Introduction}

Factor models play a fundamental role in explaining the risk premia on financial assets and serve as the benchmark for constructing investment portfolios. China has the world's second-largest stock market, but the determinants of risk premia on stocks in China remain largely unknown to both researchers and practitioners. Most research on China's stock market still follows the tradition in the US stock market by applying the three-factor model of Fama and French (FF3) [1] as the benchmark [2,3]. This may be biased considering China's unique economic and institutional environment and separation from developed markets. Liu et al. [4] reveal that the returns of the smallest stocks in China are largely related to the potential of being shells in reverse mergers instead of their fundamental values. After excluding the smallest 30\% stocks that are subject to shellvalue contamination, they propose an adjusted three-factor model $(\mathrm{CH} 3)$ that uses earning-to-price ratio to construct the value factor. They show that the $\mathrm{CH} 3$ model dominates the FF3 and is able to explain many of the financial anomalies in the Chinese stock market. However, the $\mathrm{CH} 3$ model still fails to price some important anomalies, which motivates further exploration.

In this paper, we extend the $\mathrm{CH} 3$ model of Liu et al. [4] by introducing a liquidity factor. Existing literature suggests that the liquidity risk is deemed a greater concern in China than in developed stock markets [5-7]. First, unlike developed markets that are quote-driven, China's stock market is an order-driven market without market markers. Under this circumstance, stock returns are sensitive to liquidityrelated trading costs (e.g., price impact). In addition, China's stock market is also known for its large fraction of inexperienced retail investors, who contributed to $82.01 \%$ of the total trading volume in 2018 according to the annual statistics of the Shanghai Stock Exchange. Retail investors favor 
speculative trading with short holding periods and, as a result, cannot provide stable liquidity. Moreover, government interventions may hurt market liquidity due to the transaction constraints on state-owned shares and its policy intentions for stock market stability $[7,8]$. This evidence points to the important role of stock liquidity. Motivated by the facts, we extend the $\mathrm{CH} 3$ model by introducing a liquidity factor based on the illiquidity measure of Amihud [9], which is a prevalent proxy for price impacts in emerging markets like China [10]. We show that our four-factor model outperforms the $\mathrm{CH} 3$ model, together with a set of prominent factor models that are widely recognized in developed countries.

When implementing the factor model comparison, we also note that inappropriate distributional assumptions can induce substantial bias to the results [11]. Since Fama [12], extensive literature has revealed that the distributions of stock returns have fat tails and the normality assumption is not supported by data. The normality assumption, however, has been widely applied in the asset pricing statistical inferences because of its elegant statistical properties. Specifically, $\mathrm{t}$-distribution is employed because it is the most representative fat-tailed distribution, and normality-based asset pricing theories tend to be applicable under $\mathrm{t}$-distributions [11]. We first test whether the factors and anomalies can be described by $\mathrm{t}$-distributions rather than normal distributions based on skewness and kurtosis [13]. We show that normality assumptions are strongly rejected because of the fat tails, and $t$-distributions are able to well capture such a salient feature.

In the spirit of this, we conduct the model evaluation under the alternative $\mathrm{t}$-distributions. Consistent with tests under normal distribution, we first compare our model with a set of candidate factor models by examining their ability to explain each other's factors. Utilizing the likelihood-ratio test proposed by Kan and Zhou [11], we find that our fourfactor model successfully explains all factors in the other models, while none of the existing models can subsume our four-factor model. Using the same method, we further test the candidate models' ability to price a large set of return anomalies and find that our four-factor model also outperforms the other models. Lastly, considering that the foregoing results are based on frequentist approaches, we complement the empirical analysis using a newly developed Bayesian methodology under t-distributions [14]. The results confirm that our four-factor model dominates. In addition, we also conduct the empirical tests under normality assumptions. The results show that distributional assumptions may cause substantial changes to the empirical results, but our model still outperforms.

Our contributions to the literature are mainly twofold. First, we achieve a significant improvement on the factor models in China by introducing an effective liquidity factor. Through rigorous model comparison procedures, we show that our four-factor model outperforms the prominent factor models in the literature. In particular, by surveying the most comprehensive list of anomalies for China, we confirm that our proposed factor model has superior explanatory power. Second, we contribute to the factor model comparison literature by providing evidence under alternative distributions instead of normality. Our results suggest that distributional assumptions can cause substantial changes to empirical results and reveal the necessity of considering alternative distributions in factor model studies. To the best of our knowledge, we are the first to evaluate and compare factor models under non-normal distributions for China's stock market.

\section{Literature Review}

2.1. Asset Pricing Factor Models in China. Early research on factor models in China mainly replicates the three-factor model (FF3) of Fama and French [1] and the five-factor model (FF5) of Fama and French [15]. These studies apply the Fama-French models in China and examine their performances. Yang and Chen [16], for instance, reveal the existence of size and value effects in A-share markets of China and find that the FF3 model applies to China's stock markets by fully pricing the excess returns of 25 portfolios formed based on size and book-to-market ratios. Fan and Shan [17] further verify the ability of FF3 to explain a set of anomalies including market capitalization, trading volume, book-to-market, and the ratio of A-shares to total shares. However, these studies are carried out using data of early 2000s when China's stock market was at its early stage. Hu et al. [18] point out that value effect is actually not robust in China using a longer and more recent sample. They argue that the contradiction stems from several outliers in the early years of the market and their impacts fade away in a longer sample. There are also disagreements on the advisability and effectiveness of the FF5 model in China. Zhao et al. [19] find that profitability and investment factors are not significant in China, so FF3 fits China's stock market better than FF5. However, Lin [20] points out that the profitability factor contributes significant explanatory power and FF5 consistently outperforms FF3 in China. Li et al. [21] further reveal that profitability and investment effects are both significant in China's stock markets and FF5 dominates FF3.

There are researchers who attempt to construct alternative China-specific factor models instead of simply following the US models proposed by Fama and French $[1,15]$. $\mathrm{Pan}$ and $\mathrm{Xu}$ [22] find that price-to-earnings ratio has better predictability for China's stock markets than price-to-book ratio. Based on this result, they propose an adjusted FF3 model using price-to-earnings ratio as the proxy for value. Recently, Liu et al. [4] further take the influence of shellvalue contamination into consideration. They point out that the value of the smallest stocks in Chinese market can be largely attributed to the potential of being shells in reverse mergers instead of their fundamental values. This is due to China's stringent regulations on the initial public offering (IPO) market and the high IPO costs. They find that the market values of smallest $30 \%$ percent stocks are significantly exposed to the shell-value contamination. After excluding the smallest $30 \%$ stocks, they propose an adjusted three-factor model that uses price-to-earnings ratio to construct the value factor and show that the proposed model performs well in China. 
2.2. Model Evaluation under Nonnormal Distributions. Existing research mainly evaluates factor models based on normality assumption $[1,15,23]$. Only a few have explored the implications of alternative distributions and the results are mixed.

Some early studies find no impact of distributional assumptions on empirical conclusions. Harvey and Zhou [24] investigate the mean-variance efficiency of international portfolios and find that the results are the same across normality and t-distribution assumptions. Groenewold and Fraser [25] examine the sensitivity of mean-variance analysis to iid-normality assumption using Australian data. Although the iid-normality assumption is rejected by the data, they find no difference between the results under different distribution assumptions for the unconditional CAPM, the conditional CAPM, and the APT model.

However, Zhou [26] points out that the mean-variance framework of factor models makes sense if and only if the ellipticity assumption of returns holds. The empirical results will be biased when the ellipticity assumption is maintained while normality assumption is not consistent with the data. Beaulieu et al. [27] examine several factor models' meanvariance efficiencies and ability to explain return anomalies under normal distribution and t-distribution, respectively. Their results suggest that incorporating fat tails improves the models' explanatory power in terms of pricing anomalies and the corresponding mean-variance efficiencies are less rejected. Kan and Zhou [11] provide a tractable method to estimate and evaluate factor models. They show that the normal assumption is violated for most financial assets in the US, due to the salient fat tails of their return distributions. They further find that model evaluation results can have drastic changes when switching the distributional assumption from normality to t-distribution.

\section{Methodology}

3.1. Distributional Tests. Let $x_{t}$ be the asset returns at time $t$ for an investment portfolio $x$. To test whether $\left\{x_{t}\right\}_{t=1}^{T}: T \times n$ can be described by a normal distribution, we conduct tests based on the skewness $D_{1}$ and kurtosis $D_{2}$ :

$$
\begin{aligned}
& D_{1}=\frac{1}{T^{2}} \sum_{t=1}^{T} \sum_{s=1}^{T}\left[\left(x_{t}-\widehat{\mu}\right)^{\prime} \widehat{\Sigma}^{-1}\left(x_{s}-\widehat{\mu}\right)\right]^{3}, \\
& D_{2}=\frac{1}{T} \sum_{t=1}^{T}\left[\left(x_{t}-\widehat{\mu}\right)^{\prime} \widehat{\Sigma}^{-1}\left(x_{s}-\widehat{\mu}\right)\right]^{2},
\end{aligned}
$$

where $\widehat{\mu}=(1 / T) \sum_{t=1}^{T} x_{t}$ and $\widehat{\Sigma}=(1 / T) \sum_{t=1}^{T}\left(x_{t}-\widehat{\mu}\right)\left(x_{t}-\right.$ $\widehat{\mu})^{\prime}$ are the sample mean and the covariance matrix of $\left\{x_{t}\right\}_{t=1}^{T}$, respectively. According to Kan and Zhou [11] and Mardia [13], if $x_{t}$ obeys a normal distribution, the expectation of $D_{1}$ and $D_{2}$ would be zero and three, respectively, and linear transformations of $x_{t}$ do not change the values of $D_{1}$ and $D_{2}$. Therefore, to test the normality of $x_{t}$, we can assume that its true distribution is a standard normal distribution. Then, we derive the empirical distributions of $D_{1}$ and $D_{2}$ by simulating 100,000 draws from the standard normal distribution using Markov Chain Monte Carlo (MCMC) methods and test whether $D_{1}$ and $D_{2}$ can be described by normal distributions accordingly.

This methodology also applies to test whether $x_{t}$ can be described by a t-distribution with a degree of freedom of $\nu$. In this case, the density function is

$$
f\left(x_{t}\right)=\frac{\Gamma(\nu+n / 2)}{(\pi \nu)^{n / 2} \Gamma(\nu / 2)|\Psi|^{1 / 2}}\left[1+\frac{\left(x_{t}-\mu\right)^{\prime} \Psi^{-1}\left(x_{t}-\mu\right)}{\nu}\right]^{-(\nu+n) / 2},
$$

where $\Psi=(\nu-2) \Sigma / v$ and $V$ is the covariance matrix.

3.2. The Likelihood-Ratio Method for Asset Pricing Tests under $t$-Distributions. Let $f_{t}$ be a return vector for $K$ factors and $r_{t}$ the excess returns for $N$ testing portfolios, $t=1,2, \ldots, T$. To examine whether model $f_{t}$ can explain $r_{t}$, asset pricing studies generally run the following regression:

$$
r_{t}=\alpha+\beta f_{t}+\epsilon_{t},
$$

and test the parametric restrictions for the alphas:

$$
H_{0}: \alpha_{N}=0 \text {. }
$$

If the alphas are not significantly different from zero, then we say $r_{t}$ can be explained by model $f_{t}$. Note that $r_{t}$ can be either factors from other models or return anomalies.

Assuming that $\left(f_{t}, r_{t}\right)$ follow a t-distribution with unknown degrees of freedom, Kan and Zhou [11] propose a likelihood-ratio (LR) test for (5). They show that, under the null hypothesis in (5), the corresponding LR statistics follow a Chi-square distribution asymptotically:

$$
\operatorname{LRT} \equiv 2\left(\frac{T-(N / 2)-K-1}{T}\right)\left[\log (f(\widehat{\mu}, \widehat{\Psi}, \widehat{v}))-\log \left(f\left(\widehat{\mu}_{r}, \widehat{\Psi}_{r}, \widehat{v}_{r}\right)\right)\right] \sim \chi_{N}^{2}
$$

where $f$ is the likelihood function under t-distributions as given in (3) and $(\widehat{\mu}, \widehat{\Psi}, \widehat{\nu})$ and $\left(\widehat{\mu}_{r}, \widehat{\Psi}_{r}, \widehat{\nu}_{r}\right)$ are the estimations of the means, covariance matrices, and degrees of freedom for $\left(f_{t}, r_{t}\right)$ and $r_{t}$, respectively, based on the Expectation-
Maximum algorithm in Kan and Zhou [11]. Notice that $\widehat{\Psi}$ and $\widehat{\Psi}_{r}$ are the scaled covariance matrices with $\Psi=(\widehat{\nu}-$ 2) $\Sigma / \widehat{\nu}$ and $\Psi_{r}=\left(\widehat{\nu}_{r}-2\right) \Sigma_{r} / \widehat{\nu}_{r}$, where $\Sigma$ and $\Sigma_{r}$ are the sample covariance matrices for $\left(f_{t}, r_{t}\right)$ and $r_{t}$. 
It is noteworthy that the degrees of freedom are assumed to be unknown in the above procedures. In fact, the method also applies when we specify the corresponding degrees of freedom a priori.

\subsection{Bayesian Model Comparison under t-Distributions.} Different from the frequentist approaches, Bayesian methods compare competing models in terms of their marginal likelihoods with solid theoretical basis. Higher marginal likelihoods indicate better performances in fitting real data. We adopt a recent Bayesian method of Chib and Zeng [14], which features little user-intervention and therefore helps avoid data mining.

In the Bayesian method of Chib and Zeng [14], test assets are irrelevant and we only need to focus on factors. Let $F_{t}=$ $\left(f_{t}, w_{t}\right)$ be return for $n$ traded factors at time $t$, where $f_{t}$ is the pricing model that includes $n_{f}$ factors and $w_{t}$ is the remaining $n_{w}$ factors, $n=n_{w}+n_{f}$. We assume that all factors here are under a multivariate t-distribution:

$$
F_{t} \sim \text { i.i.d. } S_{t}(\mu, \Omega, \nu),
$$

where $\mu$ is the mean vector, $\Omega$ is the variance and covariance matrix, and $\nu$ is the degree of freedom for the distribution. Equation (7) can be represented in a form of a gamma-scale mixture of normal distributions:

$$
\begin{aligned}
& F_{t} \mid \tau_{f} \sim N\left(\mu, \tau_{f}^{-1} \Omega\right), \\
& \pi\left(\tau_{f}\right)=\prod_{i=1}^{n_{f}} \Gamma\left(\tau_{f, i} \mid \frac{\nu}{2}, \frac{\nu}{2}\right) .
\end{aligned}
$$

Define the stochastic discount factor as $M_{t}=1-\left(\left(\nu_{f}\right.\right.$ $\left.-2) / \nu_{f}\right) \lambda_{f}^{\prime} \Omega_{f} \lambda_{f}\left(f_{t}-\mu_{f}\right)$, and because of the restriction that $E\left(M_{t} F_{t}\right)=0$, we have

$$
\begin{aligned}
& f_{t}=\lambda_{f}+\eta_{f, t}, \\
& w_{t}=\Gamma f_{t}+\eta_{w f, t},
\end{aligned}
$$

where $\left(\begin{array}{c}\eta_{f, t} \\ \eta_{w f, t}\end{array}\right) \mid \tau_{f, t} \sim N\left(0, \tau_{f, t}^{-1}\left(\begin{array}{cc}\Omega_{f} & 0 \\ 0 & \Omega_{w . f}\end{array}\right)\right), \Omega_{w . f}=\Omega_{w}$ $-\Omega_{f w}^{\prime} \Omega_{f}^{-1} \Omega_{f w}$.
When conducting Bayesian model comparison, we need to sample the posterior distributions of $\left(\lambda_{f}, \Omega_{f}, \Omega_{w . f}, \Gamma\right)$. To achieve this goal, we firstly need to set the prior distributions of the parameters above. However, $\left(\lambda_{f}, \Omega_{f}, \Omega_{w . f}, \Gamma\right)$ in fact includes $n_{f}+n_{f} \times n_{f}+n_{w} \times n_{w}+n_{f} \times n_{w}$ parameters. When the number of candidate factors is large, it is difficult to set the priors, and the results will be highly sensitive to the choice of priors. Therefore, Chib and Zeng [14] adopt the commonly used multivariate $\mathrm{t}$-distributions and inverse Wishart distribution as the priors of $\lambda_{f}$ and $\left(\Omega_{f}, \Omega_{w . f}, \Gamma\right)$, respectively. Under this circumstance, we can obtain the prior distributions of $\left(\lambda_{f}, \Omega_{f}, \Omega_{w . f}, \Gamma\right)$ by specifying only three parameters and selecting a subsample of $f_{t}$ as the training sample.

Specifically, let the prior of $\lambda_{f}=\left(\lambda_{1}, \lambda_{2}, \ldots, \lambda_{n_{f}}\right)$ be a multivariate t-distribution, which can be represented as a scale mixture of normal distribution:

$$
\begin{aligned}
\pi\left(\lambda_{f} \mid \tau_{\lambda}\right) & =\prod_{i=1}^{n_{f}} N\left(\lambda_{i} \mid \lambda_{0, i}, \tau_{\lambda, i}^{-1} s_{\lambda}\right), \\
\pi\left(\tau_{\lambda}\right) & =\prod_{i=1}^{n_{f}} \Gamma\left(\tau_{\lambda, i} \mid \frac{\nu_{\lambda}}{2}, \frac{\nu_{\lambda}}{2}\right),
\end{aligned}
$$

where $\lambda_{0}=\left(\lambda_{0, i}, \ldots, \lambda_{0, n_{f}}\right)$ are the sample means of the training sample, $s_{\lambda}$ is the dispersion, $\nu_{\lambda}$ is the number of degrees of freedom, and $\tau_{\lambda}$ are the latent scale randomvariables. As for the prior of $\left(\Omega_{f}, \Omega_{w . f}, \Gamma\right)$, we employ an inverse Wishart distribution:

$$
\left(\Omega_{f}, \Omega_{w . f}, \Gamma\right) \sim W^{-1}\left(\rho_{0},\left(\rho_{0}-n-1\right) \Omega_{0}\right),
$$

where $\rho_{0}$ is the number of degrees of freedom and $\Omega_{0}$ is the sample variance-covariance matrix of the training sample of $f_{t}$ scaled by $(v-2) / v$.

Based on the foregoing setup, we only need to specify the training sample of $f_{t}$ and the values of $\left(s_{\lambda}, \nu_{\lambda}, \rho_{0}\right)$ to sample the prior distributions of $\lambda_{f}$ and $\left(\Omega_{f}, \Omega_{w . f}, \Gamma\right)$. Then, we can employ the Markov Chain Monte Carlo (MCMC) method to obtain the posterior probability of $\left(\lambda_{f}, \Omega_{f}, \Omega_{w . f}, \Gamma\right)$ :

$$
\pi\left(\theta, \tau_{f}, \tau_{\lambda} \mid f\right) \propto p\left(f \mid \theta, \tau_{f}, \tau_{\lambda}\right) p\left(w \mid \theta, \tau_{f}, \tau_{\lambda}\right) \pi\left(\tau_{f}\right) \pi\left(\tau_{\lambda}\right) \pi\left(\lambda_{f} \mid \tau_{\lambda}\right) \pi\left(\Omega_{f}, \Omega_{w . f}, \Gamma\right)
$$

where $p(\cdot \mid \cdot)$ is the corresponding likelihood function. Finally, after deriving the posterior distributions, we can compute the marginal likelihood of a given model $f_{t}$. We do not report the details of MCMC sampling here and refer the interested readers to the original paper.

Following Chib and Zeng [14], we let $\rho_{0}$ be equal to $n_{f}+6, s_{\lambda}$ equal to 0.0025 , and $\nu_{\lambda}$ equal to 2.1. When sampling the priors, we repeat the sampling steps 80,000 times and discard the first 40,000 burn-in draws. The posterior distributions are obtained based on 10,000 MCMC draws beyond a burn-in of 40,000.

\section{Data}

4.1. Sample. The sample period is from January 2000 to December 2019. The trading and financial data in our paper all come from CSMAR database, except for the factors of Liu et al. [4], which are obtained from CRSP.

We include all A-share stocks of Shanghai and Shenzhen stock exchanges, whose first two digits of the unique Chinese six-digit stock identifier are 00, 30, and 60. We further impose some filters considering the economic and political background of China's stock markets following Liu et al. [4]. 
We exclude stock observations that (i) become public within six months, (ii) have less than 120 daily trading records during the past 12 months, or (iii) have less than 15 daily trading records in the last month (except for the months of the Spring Festival). These filters are set to limit the influence of IPO and long trading suspensions. Moreover, we eliminate the stocks that are in the bottom $30 \%$ size group because of the shell-value contamination following Liu et al. [4]. The proxy for size is total market capitalization including nontradable shares. We choose one-year deposit rate as the risk-free rate.

4.2. Models and Factors. The model we propose is built based on the $\mathrm{CH} 3$ model of Liu et al. [4], and we introduce a new liquidity factor. The liquidity factor, ILLIQ in this paper, is constructed as follows. In each month, we independently sort the sample stocks into two groups based on their market value, small $(S)$ and big $(B)$. We also sort stocks into three illiquidity groups based on the illiquidity measure of Amihud [9]. The most liquid $30 \%$ are defined as group $L$, most illiquid $30 \%$ are sorted into group $H$, and the rest are in group $M$. We then form six value-weighted portfolios: $S / H$, $S / M, S / L, B / H, B / M$, and $B / L$. The ILLIQ factor is defined as

$$
\operatorname{ILLIQ}=\frac{1}{2}\left(\frac{S}{H}+\frac{B}{H}\right)-\frac{1}{2}\left(\frac{S}{L}+\frac{B}{L}\right) .
$$

We therefore call this new four-factor model $\mathrm{CH} 3+$ ILLIQ as an abbreviation.

The finance literature has proposed various factor models while most of them have been ignored in the studies of China's stock markets. To better examine the performance of our model $\mathrm{CH} 3+$ ILLIQ, we compare it with several prominent factor models that are widely recognized along with the China-specific three-factor model (CH3).

Our first choice contains those well-recognized models inspired by economic and finance theory including the fivefactor model (FF5) of Fama and French [15] and the Q-factor model of Hou et al. [28]. We also choose an alternative five-factor model (FF5CP) of Fama and French [29] that replaces the accruals-based profitability factor in FF5 by a cash profitability factor. Another important criterion for choosing candidate models and factors is empirical evidence. In addition to liquidity, momentum is also one of the most studied capital market phenomena. Although literature points out that momentum strategies generally fail in China $[30,31]$, it is still worthwhile to explore momentum in the stock universe without the smallest $30 \%$ stocks. We therefore include the models that combine the abovementioned Fama-French models and momentum including Carhart [32] and the two six-factor models (FF6 and FF6CP) of Fama and French [29]. Lastly, we also incorporate the four-factor model $(\mathrm{CH} 3+\mathrm{PMO})$ of Liu et al. [4] that adds a sentiment factor PMO into $\mathrm{CH} 3$ and shows that $\mathrm{CH} 3+\mathrm{PMO}$ outperforms $\mathrm{CH} 3$.

Table 1 presents all the candidate models and their respective component factors. We replicate the factors following corresponding literature except for the factors (SMB$\mathrm{CH}$ and $\mathrm{VMG}$ ) of $\mathrm{CH} 3$, which are directly obtained from
CRSP database. Specifically, the Fama-French factors (MKT, SMB, HML, RMW, CMA) are constructed following Fama and French [15]. RMWCP of Fama and French [29] is sorted by cash profitability as opposed to RMW, which is based on accruals-based operating profitability. HMLm, as opposed to HML, uses the market cap of last month and rebalances monthly. Factors (ME, IA, ROE) from Hou et al. [28] are $2 \times 3 \times 3$ sorted. ME, sorted by market cap, and IA, sorted by the annual growth rate of total asset, are rebalanced annually. ROE is the latest reported net profit divided by book equity of last quarter. UMD is sorted by cumulative returns from $\mathrm{t}-12$ to $\mathrm{t}-2$ and monthly rebalanced. PMO from Liu et al. [4] is sorted by abnormal turnover and rebalanced monthly. All factors are value-weighted monthly long-short returns, except that UMD is equal-weighted.

4.3. Anomalies. Literature has extensively explored the anomalies in the US stock market [33], whereas related research is limited in China. Considering the importance of anomalies in evaluating asset pricing models and constructing portfolios, it is of great interest to investigate anomalies in China. Jiang et al. [34] survey a large list of stock characteristics and examine their predictability for Chinese stocks. Following their list, for each characteristic we sort the stocks into ten deciles, and the corresponding anomaly is the difference between the value-weighted returns of the highest and lowest portfolios. After excluding the characteristics that cannot be used to construct anomalies using the above procedure, we construct 65 return anomalies, and the details are provided in Table 2.

It is worth mentioning that not all the anomalies constructed will be used for model comparison. In the spirit of related literature, we only employ the anomalies that cannot be priced by CAPM under proper distributional assumptions. Since we survey the most comprehensive list of anomalies in model comparison studies for China, this also adds to the contribution to related literature. Finally, we derive a list of 15 significant anomalies that fall into four categories according to Jiang et al. [34]: (1) value-versus-growth: earnings-to-price (EP) and sales-to-price (SP); (2) profitability: return on equity (ROE), gross profitability ratio (GP), and Zscore (Z); (3) momentum: one-month reversal (REV) and change in sixmonth momentum (CHMOM); (4) trading frictions: market capitalization (MV), one-month abnormal turnover (ABTURN), one-month volatility (VOL), turnover (TURN), idiosyncratic return volatility (IVOL), maximum daily returns (MAX), price delay (PRCDEL), and market beta (BETA). The details are provided in Table 2 along with other anomalies that are explained by CAPM.

\section{Empirical Results}

In this section, we first present distributional tests on both risk factors and return anomalies. Then, under proper distributional assumptions, we report model comparison results using three approaches based on the candidate models: (1) ability to explain the factors in each other, (2) ability to price return anomalies, and (3) Bayesian marginal likelihoods. 
TABle 1: Models and factors.

\begin{tabular}{lcr}
\hline Models & Factors & References \\
\hline Q & MKT, ME, IA, ROE & Hou et al. [28] \\
FF5 & MKT, SMB, HML, CMA, RMW & Fama and French [15] \\
FF5CP & MKT, SMB, HML, CMA, RMWCP & Fama and French [29] \\
FF6 & MKT, SMB, HML, CMA, RMW, UMD & Fama and French [29] \\
FF6CP & MKT, SMB, HML, CMA, RMWCP, UMD & Fama and French [29] \\
CH3 & MKT, SMB-CH, VMG, & Liu et al. [4] \\
CH3 + PMO & MKT, SMB-CH, VMG, PMO & Liu et al. [4] \\
\hline
\end{tabular}

TABle 2: Anomalies and definitions.

\begin{tabular}{|c|c|c|c|}
\hline Acronym & Name & Reference & Details \\
\hline \multicolumn{4}{|c|}{ Panel A: value-versus-growth } \\
\hline $\mathrm{AM}$ & Asset-to-market & Fama and French [35] & Total assets/fiscal-year-end market capitalization \\
\hline DER & Debt-to-equity ratio & Bhandari [36] & Total liabilities/fiscal-year-end market capitalization \\
\hline LG & Liability growth & $\begin{array}{l}\text { Litzenberger and } \\
\text { Ramaswamy [37] }\end{array}$ & Annual growth in total liabilities \\
\hline OCFP & $\begin{array}{l}\text { Operating cash flow-to- } \\
\text { price }\end{array}$ & Desai et al. [38] & Operating cash flows/fiscal-year-end market capitalization \\
\hline PY & Payout yield & Boudoukh et al. [39] & $\begin{array}{l}\text { (Income before extraordinary items - the change of book equity)/fiscal- } \\
\text { year-end market capitalization }\end{array}$ \\
\hline Rev1 & Reversal & $\begin{array}{l}\text { De Bondt and Thaler } \\
{[40]}\end{array}$ & Cumulative returns from months $\mathrm{t}-60$ to $\mathrm{t}-13$ \\
\hline SG & Sustainable growth & $\begin{array}{l}\text { Lockwood and } \\
\text { Prombutr [41] }\end{array}$ & Annual growth in book equity \\
\hline SMI & $\begin{array}{l}\text { Sales growth minus } \\
\text { inventory growth }\end{array}$ & $\begin{array}{l}\text { Abarbanell and Bushee } \\
{[42]}\end{array}$ & Annual growth in sales - annual growth in inventory \\
\hline TG & Tax growth & $\begin{array}{l}\text { Thomas and Zhang } \\
{[43]}\end{array}$ & Annual growth in taxes payable \\
\hline $\mathrm{EP}$ & Earnings-to-price & Cakici et al. [31] & $\begin{array}{l}\text { net profit excluding nonrecurrent gains/losses (in most recent quarterly } \\
\text { financial statement)/last month-end market capitalization }\end{array}$ \\
\hline $\mathrm{BM}$ & Book-to-market equity & Wang and $\mathrm{Xu}[44]$ & $\begin{array}{c}\text { Book value of equity (in most recent quarterly financial statement)/last } \\
\text { month-end market capitalization }\end{array}$ \\
\hline $\mathrm{CP}$ & Cash flow-to-price & Cakici et al. [31] & $\begin{array}{l}\text { net change in cash or cash equivalents (between the two most recent } \\
\text { quarterly financial statements)/last month-end market capitalization }\end{array}$ \\
\hline SP & Sales-to-price & Barbee et al. [45] & $\begin{array}{c}\text { The annual operating revenue divided by fiscal-year-end market } \\
\text { capitalization }\end{array}$ \\
\hline \multicolumn{4}{|c|}{ Panel B: investment } \\
\hline ACC & Accruals & Sloan $[46]$ & $\begin{array}{c}\text { (Income before extraordinary items - operating cash flows)/average } \\
\text { total assets }\end{array}$ \\
\hline PACC & Percent accruals & Hafzalla et al. [47] & (Total profit - operating cash flow)/net profit \\
\hline $\mathrm{dBE}$ & $\begin{array}{l}\text { Change in shareholders' } \\
\text { equity }\end{array}$ & Richardson et al. [48] & Annual change in book equity/one-year-lagged total assets \\
\hline dPIA & $\begin{array}{l}\text { Changes in PPE and } \\
\text { inventory-to-assets }\end{array}$ & Lyandres et al. [49] & $\begin{array}{l}\text { (Annual change in gross property, plant, and equipment }+ \text { the annual } \\
\text { change in inventory)/one-year-lagged total assets }\end{array}$ \\
\hline IA & Investment-to-assets & Cooper et al. [50] & Annual change in total assets/one-year-lagged total assets \\
\hline IVC & Inventory change & $\begin{array}{l}\text { Thomas and Zhang } \\
\text { [51] }\end{array}$ & Annual change in inventory/average total assets \\
\hline IVG & Inventory growth & Belo and Lin [52] & Annual growth in inventory \\
\hline
\end{tabular}


TABle 2: Continued.

\begin{tabular}{|c|c|c|c|}
\hline Acronym & Name & Reference & Details \\
\hline \multicolumn{4}{|c|}{ Panel C: profitability } \\
\hline NOA & Net operating assets & Hirshleifer et al. [53] & (Operating assets - operating liabilities)/total assets \\
\hline ATO & Asset turnover & Soliman [54] & Sales/net operating assets \\
\hline CFOA & Cash flow over assets & Asness et al. [55] & Cash flow from operation/total assets \\
\hline CTO & Capital turnover & Haugen and Baker [56] & Sales/total assets \\
\hline EBIT & $\begin{array}{l}\text { Earnings before interests } \\
\text { and taxes }\end{array}$ & Greenblatt [57] & net profit + income tax expenses + financial expenses \\
\hline EY & Earnings yield & Greenblatt [57] & EBIT/enterprise value \\
\hline GM & Gross margins & Novy-Marx [58] & (Operating revenue - operating expenses)/operating revenue \\
\hline GP & Gross profitability ratio & $\begin{array}{l}\text { Novy-Marx [58] } \\
\text { Jiang et al. [59] }\end{array}$ & (Operating revenue - operating expenses)/average total assets \\
\hline NPOP & Net payout over profits & Asness et al. [55] & (net income - changes in book equity)/total profits \\
\hline ROIC & $\begin{array}{l}\text { Return on invested } \\
\text { capital }\end{array}$ & Greenblatt [57] & (EBIT - nonoperating income)/noncash enterprise value \\
\hline TBI & $\begin{array}{l}\text { Taxable income-to-book } \\
\text { income }\end{array}$ & Green et al. [60] & Pretax income/net income \\
\hline $\mathrm{Z}$ & Z-score & Dichev [61] & $\begin{array}{c}\text { Z-score }=1.2 \times(\text { working capital/total assets })+1.4 \times(\text { retained earnings } / \\
\text { total assets })+3.3 \times(\text { EBIT/total assets })+0.6 \times(\text { market value of equity } / \\
\text { book value of total liabilities })+(\text { sales/total assets })\end{array}$ \\
\hline ROE & Return on equity & Guo et al. [62] & Net earnings (in most recent quarterly financial statement)/book equity \\
\hline \multicolumn{4}{|c|}{ Panel D: momentum } \\
\hline CHMOM & $\begin{array}{l}\text { Change in 6-month } \\
\text { momentum }\end{array}$ & $\begin{array}{l}\text { Gettleman and Marks } \\
{[63]}\end{array}$ & $\begin{array}{l}\text { Cumulative returns from months } \mathrm{t}-6 \text { to } \mathrm{t}-1 \text { minus those from months } \mathrm{t}- \\
\qquad 12 \text { to } \mathrm{t}-7\end{array}$ \\
\hline MOM6M & 6-month momentum & $\begin{array}{l}\text { Jegadeesh and Titman } \\
\text { [64] }\end{array}$ & Cumulative returns from months $\mathrm{t}-6$ to $\mathrm{t}-2$ \\
\hline MOM12M & 12-month momentum & $\begin{array}{l}\text { Jegadeesh and Titman } \\
\text { [64] }\end{array}$ & Cumulative returns from months $\mathrm{t}-12$ to $\mathrm{t}-2$ \\
\hline MOM36M & 36-month momentum & $\begin{array}{l}\text { Jegadeesh and Titman } \\
\text { [64] }\end{array}$ & Cumulative returns from months $\mathrm{t}-36$ to $\mathrm{t}-13$ \\
\hline VOLT & Volume trend & Haugen and Baker [56] & $\begin{array}{l}\text { Five-year trend in monthly trading volume/five-year average trading } \\
\text { volume }\end{array}$ \\
\hline REV & 1-month reversal & Cakici et al. [31] & Cumulative returns over the month $\mathrm{t}-1$ \\
\hline \multicolumn{4}{|c|}{ Panel E: trading frictions } \\
\hline PRC & Price & Blume and Husic [65] & Share price at month $\mathrm{t}-1$ \\
\hline RVOL & RMB trading volume & Chordia et al. [66] & Natural log of RMB trading volume from month $t-2$ \\
\hline STD_RVOL & $\begin{array}{l}\text { Volatility of RMB trading } \\
\text { volume }\end{array}$ & Chordia et al. [66] & Standard deviation of daily RMB trading volume at month $\mathrm{t}-1$ \\
\hline STD_TURN & Volatility of turnover & Chordia et al. [66] & Standard deviation of daily share turnover at month $\mathrm{t}-1$ \\
\hline B_DIM & The Dimson beta & Dimson [67] & Estimated using lead, lag, and current market returns \\
\hline B_DN & Downside beta & Ang et al. [68] & $\begin{array}{l}\text { Conditional covariance between a stock's excess return and market } \\
\text { excess return/the conditional variance of market excess return } \\
\text { (condition: Market excess return is lower than the average level) }\end{array}$ \\
\hline B_FF & Fama and French beta & Fama and French [35] & $\begin{array}{c}\text { Calculated by regressing monthly returns on the current and recent lag } \\
\text { market return with a five-year rolling window }\end{array}$ \\
\hline B_FP & $\begin{array}{l}\text { Frazzini and Pedersen } \\
\text { beta }\end{array}$ & $\begin{array}{l}\text { Frazzini and Pedersen } \\
{[69]}\end{array}$ & $\begin{array}{c}\text { Return volatilities for the stock/the market return volatilities } \times \text { their } \\
\text { return correlation }\end{array}$ \\
\hline IVOL & $\begin{array}{l}\text { Idiosyncratic return } \\
\text { volatility }\end{array}$ & Ali et al. [70] & $\begin{array}{l}\text { Standard deviation of residuals of weekly returns on weekly equal- } \\
\text { weighted market returns from months t-36 to t-1 }\end{array}$ \\
\hline BETA & Market beta & $\begin{array}{l}\text { Fama and MacBeth } \\
{[71]}\end{array}$ & $\begin{array}{l}\text { Estimated market beta from weekly returns and market returns from } \\
\text { months } \mathrm{t}-36 \text { to } \mathrm{t}-1\end{array}$ \\
\hline B_HS & Hong and Sraer beta & Hong and Sraer [72] & $\begin{array}{c}\text { Summed-coefficients computed by daily returns with a one-year rolling } \\
\text { window }\end{array}$ \\
\hline ILLIQ & Illiquidity & Amihud [9] & $\begin{array}{l}\text { Average of (absolute daily return/daily RMB trading volume) over the } \\
\text { past } 12 \text { months ending on June } 30\end{array}$ \\
\hline PRCDEL & Price delay & $\begin{array}{l}\text { Hou and Moskowitz } \\
\qquad[73]\end{array}$ & $\begin{array}{c}\text { The proportion of variation in weekly returns from months } \mathrm{t}-36 \text { to } \mathrm{t}-1 \\
\text { explained by } 4 \text { lags of weekly market returns incremental to } \\
\text { contemporaneous market returns }\end{array}$ \\
\hline
\end{tabular}


TABLE 2: Continued.

\begin{tabular}{|c|c|c|c|}
\hline Acronym & Name & Reference & Details \\
\hline TURN3 & 3-month share turnover & Datar et al. [74] & $\begin{array}{c}\text { Average monthly trading volume for } 3 \text { months/number of shares } \\
\text { outstanding }\end{array}$ \\
\hline MV & Firm size & Wang and $\mathrm{Xu}[44]$ & Market value at month $\mathrm{t}-1$ \\
\hline STD & One-month volatility & Cakici et al. [31] & Standard deviation of daily returns over the month $t-1$ \\
\hline MAX & Maximum daily returns & Carpenter et al. [75] & Maximum of daily returns over month $\mathrm{t}-1$ \\
\hline TURN & Twelve-month turnover & Liu et al. [4] & Average daily share turnover over the past one year \\
\hline ABTURN & $\begin{array}{l}\text { One-month abnormal } \\
\text { turnover }\end{array}$ & Liu et al. [4] & $\begin{array}{l}\text { Average daily turnover over the past one month/average daily turnover } \\
\text { over the past one year }\end{array}$ \\
\hline \multicolumn{4}{|c|}{ Panel F: intangibles } \\
\hline AGE & Firm age & Jiang et al. [76] & Number of years since IPO year \\
\hline CFD & Cash flow-to-debt & Ou and Penmar & $\begin{array}{l}\text { Earnings before depreciation and extraordinary items/average total } \\
\qquad \text { liabilities }\end{array}$ \\
\hline CR & Curr & $\mathrm{Ou} \mathrm{a}$ & Current assets/current liabilities \\
\hline CRG & Current ratio growth & Ou and Penman [77] & Annual growth in current ratio \\
\hline QR & Quick ratio & Ou and Penman [77] & (Current assets - inventory)/current liabilities \\
\hline QRG & Quick ratio growth & Ou and Penman [77] & Annual growth in quick ratio \\
\hline SI & Sales-to-inventory & Ou and Penman [77] & Sales/total inventory \\
\hline
\end{tabular}

5.1. Distributional Tests. First of all, we use the method in Section 3.1 to test whether the factors and anomalies can be described by normality or t-distributions based on skewness and kurtosis. It is noteworthy that we need to specify the degrees of freedom (d.f.), which are larger than 2, for $\mathrm{t}$-distributions. The larger the d.f., the more the similarities between $t$-distributions and normality. For robustness concerns, we set the d.f. to be $3,4,5,8,16$, and 32 , and we find that $\mathrm{t}$-distributions with small d.f. tend to fit the data better. For conciseness, we only report the results corresponding to the d.f. of 3 in this section. Our results are robust to appropriate alternative parameter values.

We first test the distributional hypothesis of each factor, respectively. The univariate tests of the 14 factors are presented in Table 3 . We can see that each factor has a kurtosis that is higher than 3 , which indicates a fat-tail distribution. The statistical tests for kurtosis show that the normality assumptions are all rejected at the $1 \%$ significance level, while none of the $t$-distribution assumptions is rejected. In terms of the skewness tests, we can see that all the factors can be described by $\mathrm{t}$-distributions whereas only half of the factors satisfy normality assumptions. We also conduct the same tests for the return anomalies and find similar results. (We do not report the univariate tests of the anomalies out of readability concerns since we have 65 anomalies in total. The results are available upon request.)

Considering that related empirical analysis mainly relies on the joint distributions of factors and anomalies, it is necessary to test the multivariate kurtosis and skewness as well. Note that, following literature, we only employ the anomalies that cannot be priced by CAPM at the 5\% significance level for empirical analysis. Based on the results above, we test whether the anomalies can be priced by CAPM under $t$-distributions, of which the degrees of freedom are assumed to be unknown and estimated based on the methods as illustrated in Section 3.2.

Table 4 presents the multivariate tests for the candidate factors and the 15 anomalies that cannot be explained by CAPM. Consistent with the univariate tests, we also set the degrees of freedom to be 3. Given the results of the univariate tests, it is not surprising to see the strong rejection of normality assumptions in terms of both skewness and kurtosis. On the other hand, both the joint distributions of factors and anomalies advocate the use of t-distributions.

In sum, fat tails are a nonnegligible feature of factors and anomalies and deserve serious investigations in related studies. We therefore choose $\mathrm{t}$-distributions as the alternative distributional assumption for normal distributions in the following model comparison analysis.

5.2. Model Comparison. As discussed earlier, we propose a four-factor model (CH3 + ILLIQ) that combines the threefactor model $(\mathrm{CH} 3)$ of Liu et al. [4] and an liquidity factor (ILLIQ) that is constructed based on Amihud [9] illiquidity measure. A main goal of this paper is to examine whether the $\mathrm{CH} 3$ + ILLIQ model outperforms existing factor models. In this section, we compare the candidate models based on their ability to explain the factors in each other and the anomalies, as well as Bayesian marginal likelihoods.

All the empirical tests are carried out under t-distributions and, therefore, we need to specify the d.f. for each test. To ensure that our results are consistent with each other, we use the optimal d.f. of the joint distribution of the 14 candidate factors and 15 anomalies throughout the empirical analysis. Based on the Expectation-Maximum method of Kan and Zhou [11], the corresponding optimal d.f. is set to be 3.2462 .

5.2.1. Redundancy Tests for the Factors in CH3+ILLIQ. Before any formal comparison, we first need to check the redundancy of the ILLIQ factor in the CH3 + ILLIQ model, i.e., whether ILLIQ can be explained by $\mathrm{CH} 3$. To this end, we use the method of Section 3.2 to test whether the intercept of ILLIQ with respect to $\mathrm{CH} 3$ is significant. As shown in column (1) of Table 5, the corresponding intercept is significantly different from zero. This suggests that the new factor ILLIQ is not redundant and brings additional 
TABLE 3: Univariate distributional tests.

\begin{tabular}{|c|c|c|c|c|c|c|}
\hline \multirow{2}{*}{ Factor } & \multirow{2}{*}{ Skewness } & \multicolumn{2}{|c|}{$p$-value } & \multirow{2}{*}{ Kurtosis } & \multicolumn{2}{|c|}{$p$-value } \\
\hline & & $H_{0}:$ normal & $H_{0}: t$ & & $H_{0}:$ normal & $H_{0}: t$ \\
\hline MKT & -0.24 & 0.14 & 0.81 & 4.00 & $<0.01$ & 0.99 \\
\hline SMB & -0.39 & 0.02 & 0.70 & 5.90 & $<0.01$ & 0.81 \\
\hline HML & -0.21 & 0.18 & 0.83 & 8.56 & $<0.01$ & 0.54 \\
\hline RMW & -0.54 & $<0.01$ & 0.60 & 7.05 & $<0.01$ & 0.68 \\
\hline RMWCP & -0.53 & $<0.01$ & 0.60 & 7.04 & $<0.01$ & 0.68 \\
\hline CMA & 0.16 & 0.32 & 0.87 & 4.84 & $<0.01$ & 0.93 \\
\hline $\mathrm{ME}$ & -0.50 & $<0.01$ & 0.63 & 7.70 & $<0.01$ & 0.62 \\
\hline IA & 0.32 & 0.05 & 0.75 & 4.41 & $<0.01$ & 0.97 \\
\hline ROE & 0.08 & 0.63 & 0.94 & 5.10 & $<0.01$ & 0.91 \\
\hline $\mathrm{SMB}-\mathrm{CH}$ & 0.06 & 0.71 & 0.95 & 5.06 & $<0.01$ & 0.91 \\
\hline VMG & 0.20 & 0.21 & 0.84 & 4.42 & $<0.01$ & 0.97 \\
\hline PMO & -0.82 & $<0.01$ & 0.45 & 9.87 & $<0.01$ & 0.45 \\
\hline UMD & -0.02 & 0.91 & 0.98 & 4.41 & $<0.01$ & 0.97 \\
\hline ILLIQ & -0.34 & 0.04 & 0.73 & 8.99 & $<0.01$ & 0.51 \\
\hline
\end{tabular}

TABLE 4: Multivariate distributional tests.

\begin{tabular}{lcccccc}
\hline & & \multicolumn{2}{c}{$p$-value } & Kurtosis & \multicolumn{2}{c}{$p$-value } \\
& Skewness & $H_{0}:$ & $H_{0}:$ & & $H_{0}:$ & $H_{0}:$ \\
& & Normal & $t$ & & Normal & $t$ \\
\hline Factors & 25.59 & $<0.01$ & 0.99 & 284.42 & $<0.01$ & 0.99 \\
Anomalies & 134.31 & $<0.01$ & 0.17 & 605.03 & $<0.01$ & 0.65 \\
\hline
\end{tabular}

information to the baseline $\mathrm{CH} 3$ model. Likewise, we also test the redundancies of the remaining three factors, MKT, $\mathrm{SMB}-\mathrm{CH}$, and VMG, and the results in columns (2) to (4) show that none of them is redundant.

The redundancy tests above also help justify the validity of $\mathrm{CH} 3$ + ILLIQ and confirm that $\mathrm{CH} 3$ + ILLIQ outperforms $\mathrm{CH} 3$ in the spirit of Fama and French [15, 29] and Hou et al. $[23,28]$.

5.2.2. Explaining Factors. We proceed to compare the candidate models based on their ability to explain the factors in each other. Specifically, to test whether model A can explain model B, we regress the exclusive factors in B on A and test whether the intercepts are jointly zero using the LR method in Section 3.2 under t-distributions. A is considered to outperform $\mathrm{B}$ if the corresponding intercepts are not significant. Table 6 gives the results using CH3 + ILLIQ as the benchmark. (It is worth mentioning that this section involves pairwise model comparison, and the LR statistics therefore may not be comparable across model pairs due to the different number of factors in each regression.) We can see that all the other candidate models fail to explain $\mathrm{CH} 3+$ ILLIQ with $p$-values smaller than $10^{-4}$. In contrast, $\mathrm{CH} 3+$ ILLIQ can explain all the other candidate models in the sense that none of their intercepts with respect to $\mathrm{CH} 3+$ ILLIQ are statistically significant at the $10 \%$ significance level. In particular, while Liu et al. [4] show that their four-factor model $\mathrm{CH} 3+\mathrm{PMO}$ outperforms $\mathrm{CH} 3$, our results show that $\mathrm{CH} 3+$ ILLIQ dominates $\mathrm{CH} 3+\mathrm{PMO}$ significantly. In sum, these results indicate that $\mathrm{CH} 3+$ ILLIQ dominates other candidate models in terms of explaining the factors in each other.
TABLE 5: Redundancy tests for the factors in CH3 + ILLIQ.

\begin{tabular}{lcccc}
\hline$H_{0}: \alpha=0$ & $(1)$ & $(2)$ & $(3)$ & $(4)$ \\
& ILLIQ & MKT & SMB-CH & VMG \\
\hline LR statistic & 29.57 & 4.06 & 3.85 & 71.83 \\
$p$-value & $<0.01$ & 0.04 & 0.05 & $<0.01$ \\
\hline
\end{tabular}

5.2.3. Explaining Anomalies. We further evaluate the performances of the factor models in terms of their ability to explain the 15 significant anomalies, which are presented in Section 4.3. The left panel of Table 7 presents the LR tests for the intercepts of regressing the anomalies jointly on the candidate models using the method in Section 3.2 under $\mathrm{t}$-distributions. We can see that only CH3 + ILLIQ succeeds in explaining all 15 anomalies, whereas all the other candidate models fail to do so at the 5\% significance level. To examine whether the t-distribution assumption is essential, we also conduct analogous tests under normality assumptions using the classical GRS test of Gibbons et al. [78]. The estimation results are reported on the right panel of Table 7. We find that the normal assumption may have an inclination to overestimate the explanatory power of models: both $\mathrm{CH} 3+$ ILLIQ and $\mathrm{CH} 3+\mathrm{PMO}$ can explain the candidate anomalies jointly. These results indicate that distributional assumptions can have a large impact on model comparison. Since the ability to explain anomalies is one of the most important criteria for factor model evaluation, this further verifies the necessity of using proper distributional assumptions in related studies.

To further explore the details, we present the results of univariate analysis by regressing each anomaly on the candidate models, respectively. In Table 8 , we only report each anomaly's alphas with respect to $\mathrm{CH} 3+$ ILLIQ, $\mathrm{CH} 3+\mathrm{PMO}$, and $\mathrm{CH} 3$, which are the top three candidates according to Table 7 . We can see that the t-distribution seems to provide more strict anomaly tests. Under normality assumptions, $\mathrm{CH} 3+\mathrm{PMO}$ only fails to explain $\mathrm{MV}$ at the $10 \%$ significance; however, it fails to price three different anomalies under $\mathrm{t}$-distributions. As for $\mathrm{CH} 3$, the anomalies unexplained remain the same across distributional 
TABLE 6: Candidate models' ability to explain the factors in each other.

\begin{tabular}{|c|c|c|c|c|}
\hline & \multicolumn{2}{|c|}{$\begin{array}{l}\text { Other models' ability to explain } \\
\text { CH3 + ILLIQ }\end{array}$} & \multicolumn{2}{|c|}{$\begin{array}{l}\text { CH3 + ILLIQ's ability to explain the } \\
\text { other models }\end{array}$} \\
\hline & LR statistic & $p$-value & LR statistic & $p$-value \\
\hline $\mathrm{Q}$ & 65.45 & $<10^{-13}$ & 4.36 & 0.23 \\
\hline FF5 & 75.80 & $<10^{-15}$ & 6.12 & 0.19 \\
\hline FF5CP & 77.51 & $<10^{-15}$ & 5.19 & 0.27 \\
\hline FF6 & 86.28 & $<10^{-17}$ & 8.84 & 0.12 \\
\hline FF6CP & 86.66 & $<10^{-17}$ & 8.67 & 0.12 \\
\hline $\mathrm{CH} 3+\mathrm{PMO}$ & 17.18 & $<10^{-4}$ & 1.40 & 0.24 \\
\hline
\end{tabular}

TABLE 7: Candidate models' ability to explain the anomalies jointly.

\begin{tabular}{|c|c|c|c|c|}
\hline & \multicolumn{2}{|c|}{ t-Distribution } & \multicolumn{2}{|c|}{ Normal distribution } \\
\hline & LR statistic & $p$-value & GRS statistic & $p$-value \\
\hline Q & 69.97 & $<10^{-8}$ & 4.23 & $<10^{-6}$ \\
\hline FF5 & 80.97 & $<10^{-10}$ & 5.32 & $<10^{-8}$ \\
\hline FF5CP & 77.67 & $<10^{-9}$ & 5.93 & $<10^{-9}$ \\
\hline FF6 & 85.36 & $<10^{-11}$ & 5.64 & $<10^{-8}$ \\
\hline FF6CP & 78.02 & $<10^{-9}$ & 6.09 & $<10^{-9}$ \\
\hline $\mathrm{CH} 3$ & 36.71 & 0.001 & 1.88 & 0.03 \\
\hline $\mathrm{CH} 3+\mathrm{PMO}$ & 24.85 & 0.05 & 1.43 & 0.13 \\
\hline CH3 + ILLIQ & 21.85 & 0.11 & 1.38 & 0.16 \\
\hline
\end{tabular}

TABLE 8: Candidate models' ability to explain the anomalies: univariate tests.

\begin{tabular}{|c|c|c|c|c|c|c|}
\hline & \multicolumn{3}{|c|}{ Alpha (\%) under t-Distribution } & \multicolumn{3}{|c|}{ Alpha (\%) under normal distribution } \\
\hline & CH3 + ILLIQ & $\mathrm{CH} 3+\mathrm{PMO}$ & $\mathrm{CH} 3$ & $\mathrm{CH} 3+$ ILLIQ & $\mathrm{CH} 3+\mathrm{PMO}$ & $\mathrm{CH} 3$ \\
\hline ABTURN & 0.36 & 0.33 & $1.00^{* * *}$ & 0.41 & 0.30 & $1.14^{* * *}$ \\
\hline MV & 0.27 & 0.24 & $0.33^{* *}$ & 0.32 & $0.34^{*}$ & $0.35^{*}$ \\
\hline TURN & 0.08 & -0.25 & $-0.69^{* *}$ & 0.05 & -0.20 & $-0.62^{*}$ \\
\hline ROE & 0.41 & $0.62^{* *}$ & 0.44 & 0.30 & 0.34 & 0.29 \\
\hline STD & -0.24 & $-0.52^{*}$ & 0.08 & 0.03 & -0.19 & 0.33 \\
\hline MAX & -0.29 & $-0.43^{*}$ & 0.05 & -0.24 & -0.39 & 0.14 \\
\hline SP & 0.44 & 0.14 & 0.25 & $0.76^{*}$ & 0.57 & 0.48 \\
\hline BETA & 0.01 & -0.10 & -0.34 & 0.07 & 0.04 & -0.20 \\
\hline CHMOM & 0.27 & 0.23 & 0.03 & -0.12 & -0.02 & -0.40 \\
\hline $\mathrm{EP}$ & 0.19 & 0.11 & 0.02 & 0.13 & 0.15 & 0.02 \\
\hline GP & 0.23 & 0.28 & 0.35 & 0.39 & 0.35 & 0.50 \\
\hline IVOL & 0.01 & 0.03 & -0.28 & -0.44 & -0.48 & -0.44 \\
\hline PRCDEL & -0.18 & -0.14 & -0.39 & -0.09 & -0.04 & -0.22 \\
\hline REV & 0.11 & -0.11 & 0.28 & -0.06 & -0.30 & 0.30 \\
\hline Z & 0.09 & 0.24 & 0.29 & 0.06 & 0.15 & 0.38 \\
\hline
\end{tabular}

Note. ${ }^{* * *},{ }^{* *}$, and ${ }^{*}$ denote significance at $1 \%, 5 \%$, and $10 \%$, respectively.

assumptions but CH3's performance is evidently weaker under $\mathrm{t}$-distributions. These results further underscore the importance of using proper distributional assumptions.

In sum, the results above show that $\mathrm{CH} 3$ + ILLIQ outperforms other candidate models in terms of explaining return anomalies.

5.2.4. Bayesian Model Comparison. Lastly, considering that the above results are based on frequentist approaches, we complement the empirical analysis from a Bayesian perspective using the newly developed method of Chib and Zeng [14]. The Bayesian method enables us to directly rank a set of candidate models according to their marginal likelihoods. A higher marginal likelihood would indicate a better performance in terms of explanatory power and fitness.

We conduct the tests under two alternative distributions, respectively. The left panel of Table 9 gives the log marginal likelihoods of the candidate models under t-distribution assumptions. To be consistent with the above analysis, the degree of freedom in the Bayesian analysis is also set to be 3.2464. The results show that $\mathrm{CH} 3+$ ILLIQ produces the highest marginal likelihood and outperforms all other candidate models. Notice that even though the log differences between $\mathrm{CH} 3$ + ILLIQ and the other models are seemingly small, the implied gaps are actually quite large. For example, a difference of 6.09 between $\mathrm{CH} 3+$ ILLIQ's and 
TABLE 9: Bayesian marginal likelihoods.

\begin{tabular}{lcc}
\hline & \multicolumn{2}{c}{$\log$ (marginal likelihood) } \\
& $t$-Distribution & Normal distribution \\
\hline Q & 7435.64 & 7121.88 \\
FF5 & 7426.22 & 7111.24 \\
FF5CP & 7422.96 & 7107.92 \\
FF6 & 7424.90 & 7108.21 \\
FF6CP & 7423.19 & 7105.48 \\
CH3 & 7455.77 & 7142.42 \\
CH3 + PMO & 7461.53 & 7144.79 \\
CH3 + ILLIQ & 7467.62 & 7149.10 \\
\hline
\end{tabular}

$\mathrm{CH} 3+$ PMO's log marginal likelihoods implies that the marginal likelihood of $\mathrm{CH} 3+$ ILLIQ is 440 times higher than that of $\mathrm{CH} 3+\mathrm{PMO}$. We also present the Bayesian model comparison results under normality assumptions on the right panel of Table 9 and find that $\mathrm{CH} 3+$ ILLIQ still dominates other models with the highest marginal likelihood. Moreover, the marginal likelihoods are comparable across different distributional assumptions, and we can see that the marginal likelihood under normality is far smaller than that under t-distributions for all models. This also justifies the usage of t-distributions as the alternative to normality in factor model studies from a Bayesian perspective.

In sum, our four-factor model CH3 + ILLIQ dominates the other candidate models in the sense of Bayesian marginal likelihoods.

\section{Conclusions}

Motivated by the fact that liquidity plays an important role in Chinese stock market, we propose a four-factor model that extends the three-factor model $(\mathrm{CH} 3)$ of Liu et al. [4] by introducing a liquidity factor. As suggested by distributional tests, we take into account the fat-tail features of stock returns and compare our four-factor model with a set of prominent factor models under t-distributions using newly developed likelihood-ratio tests and Bayesian methods. Under t-distributions, our model comparison results show that our four-factor model significantly outperforms the other competing models in terms of explaining the factors in the other models and anomalies, as well as Bayesian marginal likelihoods. Our results also indicate that distributional assumptions may cause significant changes to model comparison results and therefore advocate the use of proper distributions instead of normality.

Our paper contributes to the literature by proposing a more effective four-factor model for China. Through rigorous model comparisons, we find that our four-factor model outperforms the prominent factor models from the existing literature. In particular, by surveying the most comprehensive list of anomalies for China in related literature, we find that our factor model has a strong explanatory power on return anomalies. Besides, we provide supporting evidence for $\mathrm{t}$-distribution assumption in factor model comparisons. We show that different distribution assumptions can cause substantial changes to empirical results and reveal the necessity of considering alternative distributions in factor model studies.

\section{Data Availability}

The data used to support the findings of this study are available upon request.

\section{Conflicts of Interest}

The authors declare that they have no conflicts of interest regarding the publication of this paper.

\section{Acknowledgments}

This research was funded by National Natural Science Foundation of China (grant no. 71672079).

\section{References}

[1] E. F. Fama and K. R. French, "Common risk factors in the returns on stocks and bonds," Journal of Financial Economics, vol. 33, no. 1, pp. 3-56, 1993.

[2] C. Wang and S. Chin, "Profitability of return and volumebased investment strategies in China's stock market," PacificBasin Finance Journal, vol. 12, no. 5, pp. 541-564, 2004.

[3] X. Chen, K. A. Kim, T. Yao, and T. Yu, "On the predictability of Chinese stock returns," Pacific-Basin Finance Journal, vol. 18, no. 4, pp. 403-425, 2010.

[4] J. Liu, R. F. Stambaugh, and Y. Yuan, "Size and value in China," Journal of Financial Economics, vol. 134, no. 1, pp. 48-69, 2019.

[5] P. K. Narayan, Z. Zhang, and X. Zheng, "Some hypotheses on commonality in liquidity: new evidence from the Chinese stock market," Emerging Markets Finance and Trade, vol. 51, no. 5, pp. 915-944, 2015.

[6] P. K. Narayan and X. Zheng, "Market liquidity risk factor and financial market anomalies: evidence from the Chinese stock market," Pacific-Basin Finance Journal, vol. 18, no. 5, pp. 509-520, 2010.

[7] S. Li, T. Zhang, and Y. Li, "Flight-to-liquidity: evidence from China's stock market," Emerging Markets Review, vol. 38, pp. 159-181, 2019.

[8] P. K. Narayan and X. Zheng, "The relationship between liquidity and returns on the Chinese stock market," Journal of Asian Economics, vol. 22, no. 3, pp. 259-266, 2011.

[9] Y. Amihud, "Illiquidity and stock returns: cross-section and time-series effects," Journal of Financial Markets, vol. 5, no. 1, pp. 31-56, 2002.

[10] W. Kang and H. Zhang, "Measuring liquidity in emerging markets," Pacific-Basin Finance Journal, vol. 27, no. 4, pp. 49-71, 2014.

[11] R. Kan and G. Zhou, "Modeling non-normality using multivariate t: implications for asset pricing," China Finance Review International, vol. 7, no. 1, pp. 22-32, 2017.

[12] E. F. Fama, "The behavior of stock-market prices," The Journal of Business, vol. 38, no. 1, pp. 34-105, 1965.

[13] K. V. Mardia, "Measures of multivariate skewness and kurtosis with applications," Biometrika, vol. 57, no. 3, pp. 519-530, 1970. 
[14] S. Chib and X. Zeng, "Which factors are risk factors in asset pricing? A model scan framework," Journal of Business \& Economic Statistics, vol. 38, no. 4, pp. 771-783, 2020.

[15] E. F. Fama and K. R. French, "A five-factor asset pricing model," Journal of Financial Economics, vol. 116, no. 1, pp. 1-22, 2015.

[16] X. Yang and Z. Chen, "An empirical analysis of the threefactor model in China," Quantitative Economics Review, vol. 122003, in Chinese.

[17] L. Fan and Y. Shan, "Trading volume, valuation ratio, momentum, and a three-factor model," Journal of Management Science, vol. 7, pp. 13-22, 2004, in Chinese.

[18] G. X. Hu, C. Chen, Y. Shao, and J. Wang, "Fama-French in China: size and value factors in Chinese stock returns," International Review of Finance, vol. 19, no. 1, pp. 3-44, 2019.

[19] S. Zhao, H. Yan, and K. Zhang, "Does Fama-French five factor model outperform three factor model? Evidence from China's A-share market?" Nankai Economic Studies, vol. 2, pp. 41-59, 2016, in Chinese.

[20] Q. Lin, "Noisy prices and the Fama-French five-factor asset pricing model in China," Emerging Markets Review, vol. 31, pp. 141-163, 2017.

[21] Z. Li, G. Yang, G. Feng, and L. Jing, "Fama-French five factor model in China stock market," Journal of Financial Research, vol. 6, pp. 191-206, 2017, in Chinese.

[22] L. Pan and J. Xu, "Risk factors in China's A-share stock market," Journal of Financial Research, vol. 10, pp. 140-154, 2011, in Chinese.

[23] K. Hou, H. Mo, C. Xue, and L. Zhang, "Which factors?" Review of Finance, vol. 23, no. 1, pp. 1-35, 2019.

[24] C. R. Harvey and G. Zhou, "International asset pricing with alternative distributional specifications," Journal of Empirical Finance, vol. 1, no. 1, pp. 107-131, 1993.

[25] N. Groenewold and P. Fraser, "Tests of asset-pricing models: how important is the iid-normal assumption?" Journal of Empirical Finance, vol. 8, no. 4, pp. 427-449, 2001.

[26] G. Zhou, "Asset-pricing tests under alternative distributions," The Journal of Finance, vol. 48, no. 5, pp. 1927-1942, 1993.

[27] M.-C. Beaulieu, J.-M. Dufour, and L. Khalaf, "Asset-pricing anomalies and spanning: multivariate and multifactor tests with heavy-tailed distributions," Journal of Empirical Finance, vol. 17, no. 4, pp. 763-782, 2010.

[28] K. Hou, C. Xue, and L. Zhang, "Digesting anomalies: an investment approach," Review of Financial Studies, vol. 28, no. 3, pp. 650-705, 2015.

[29] E. F. Fama and K. R. French, "Choosing factors," Journal of Financial Economics, vol. 128, no. 2, pp. 234-252, 2018.

[30] M. A. Cheema and G. V. Nartea, "Momentum returns and information uncertainty: evidence from China," Pacific-Basin Finance Journal, vol. 30, pp. 173-188, 2014.

[31] N. Cakici, K. Chan, and K. Topyan, "Cross-sectional stock return predictability in China," The European Journal of Finance, vol. 23, no. 7-9, pp. 581-605, 2017.

[32] M. M. Carhart, "On persistence in mutual fund performance," The Journal of Finance, vol. 52, no. 1, pp. 57-82, 1997.

[33] K. Hou, C. Xue, and L. Zhang, "Replicating anomalies," The Review of Financial Studies, vol. 33, no. 5, pp. 2019-2133, 2020.

[34] F. Jiang, G. Tang, and G. Zhou, "Firm characteristics and Chinese stocks," Journal of Management Science and Engineering, vol. 3, no. 4, pp. 259-283, 2018, in Chinese.

[35] E. F. Fama and K. R. French, "The cross-section of expected stock returns," The Journal of Finance, vol. 47, no. 2, pp. 427-465, 1992.
[36] L. C. Bhandari, "Debt/equity ratio and expected common stock returns: empirical evidence," The Journal of Finance, vol. 43, no. 2, pp. 507-528, 1988.

[37] R. H. Litzenberger and K. Ramaswamy, "The effects of dividends on common stock prices tax effects or information effects?" The Journal of Finance, vol. 37, no. 2, pp. 429-443, 1982.

[38] H. Desai, S. Rajgopal, and M. Venkatachalam, "Valueglamour and accruals mispricing: one anomaly or two?" The Accounting Review, vol. 79, no. 2, pp. 355-385, 2004.

[39] J. Boudoukh, R. Michaely, M. Richardson, and M. R. Roberts, "On the importance of measuring payout yield: implications for empirical asset pricing," The Journal of Finance, vol. 62, no. 2, pp. 877-915, 2007.

[40] W. F. M. De Bondt and R. Thaler, "Does the stock market overreact?” The Journal of Finance, vol. 40, no. 3, pp. 793-805, 1985.

[41] L. Lockwood and W. Prombutr, "Sustainable growth and stock returns," Journal of Financial Research, vol. 33, no. 4, pp. 519-538, 2010.

[42] J. S. Abarbanell and B. J. Bushee, "Abnormal returns to a fundamental analysis strategy," Accounting Review, vol. 73, no. 1, pp. 19-45, 1998.

[43] J. Thomas and F. X. Zhang, "Tax expense momentum," Journal of Accounting Research, vol. 49, no. 3, pp. 791-821, 2011.

[44] F. Wang and Y. Xu, "What determines Chinese stock returns?” Financial Analysts Journal, vol. 60, no. 6, pp. 65-77, 2004.

[45] W. C. Barbee Jr., S. Mukherji, and G. A. Raines, "Do salesprice and debt-equity explain stock returns better than bookmarket and firm size?" Financial Analysts Journal, vol. 52, no. 2, pp. 56-60, 1996.

[46] R. G. Sloan, "Do stock prices fully reflect information in accruals and cash flows about future earnings," The Accounting Review, vol. 71, no. 3, pp. 289-315, 1998.

[47] N. Hafzalla, R. Lundholm, and E. Matthew Van Winkle, "Percent accruals," The Accounting Review, vol. 86, no. 1, pp. 209-236, 2011.

[48] S. A. Richardson, R. G. Sloan, M. T. Soliman, and İ. Tuna, "Accrual reliability, earnings persistence and stock prices," Journal of Accounting and Economics, vol. 39, no. 3, pp. 437-485, 2005.

[49] E. Lyandres, L. Sun, and L. Zhang, "The new issues puzzle: testing the investment-based explanation," Review of Financial Studies, vol. 21, no. 6, pp. 2825-2855, 2008.

[50] M. J. Cooper, H. Gulen, and M. J. Schill, "Asset growth and the cross-section of stock returns," The Journal of Finance, vol. 63, no. 4, pp. 1609-1651, 2008.

[51] J. K. Thomas and H. Zhang, "Inventory changes and future returns," Review of Accounting Studies, vol. 7, no. 1, pp. 163-187, 2002.

[52] F. Belo and X. Lin, "The inventory growth spread," Review of Financial Studies, vol. 25, no. 1, pp. 278-313, 2012.

[53] D. Hirshleifer, K. Kewei Hou, S. H. Teoh, and Y. Yinglei Zhang, "Do investors overvalue firms with bloated balance sheets?" Journal of Accounting and Economics, vol. 38, no. 1, pp. 297-331, 2004.

[54] M. T. Soliman, "The use of dupont analysis by market participants," The Accounting Review, vol. 83, no. 3, pp. 823-853, 2008.

[55] C. S. Asness, A. Frazzini, and L. H. Pedersen, "Quality minus junk," Review of Accounting Studies, vol. 24, no. 1, pp. 34-112, 2019. 
[56] R. A. Haugen and N. L. Baker, "Commonality in the determinants of expected stock returns," Journal of Financial Economics, vol. 41, no. 3, pp. 401-439, 1996.

[57] J. Greenblatt, The Little Book that Beats the Market, John Wiley \& Sons, Hoboken, NJ, USA, 2006.

[58] R. Novy-Marx, "The other side of value: the gross profitability premium," Journal of Financial Economics, vol. 108, no. 1, pp. 1-28, 2013.

[59] F. Jiang, X. Qi, and G. Tang, "Q-theory, mispricing, and profitability premium: evidence from China," Journal of Banking \& Finance, vol. 87, no. 2, pp. 135-149, 2018.

[60] J. Green, J. R. M. Hand, and X. F. Zhang, "The supraview of return predictive signals," Review of Accounting Studies, vol. 18, no. 3, pp. 692-730, 2013.

[61] I. D. Dichev, "Is the risk of bankruptcy a systematic risk?" The Journal of Finance, vol. 53, no. 3, pp. 1131-1147, 1998.

[62] B. Guo, W. Zhang, Y. Zhang, and H. Zhang, "The five-factor asset pricing model tests for the Chinese stock market," Pacific-basin Finance Journal, vol. 43, pp. 84-106, 2017.

[63] E. Gettleman and J. M. Marks, “Acceleration strategies," SSRN Electronic Journal, 2006.

[64] N. Jegadeesh and S. Titman, "Returns to buying winners and selling losers: implications for stock market efficiency," The Journal of Finance, vol. 48, no. 1, pp. 65-91, 1993.

[65] M. E. Blume and F. Husic, "Price, beta, and exchange listing," The Journal of Finance, vol. 28, no. 2, pp. 283-299, 1973.

[66] T. Chordia, A. Subrahmanyam, and V. R. Anshuman, "Trading activity and expected stock returns," Journal of Financial Economics, vol. 59, no. 1, pp. 3-32, 2001.

[67] E. Dimson, "Risk measurement when shares are subject to infrequent trading," Journal of Financial Economics, vol. 7, no. 2, pp. 197-226, 1979.

[68] A. Ang, J. Chen, and Y. Xing, "Downside risk," Review of Financial Studies, vol. 19, no. 4, pp. 1191-1239, 2006.

[69] A. Frazzini and L. H. Pedersen, "Betting against beta," Journal of Financial Economics, vol. 111, no. 1, pp. 1-25, 2014.

[70] A. Ali, L.-S. Hwang, and M. A. Trombley, "Arbitrage risk and the book-to-market anomaly," Journal of Financial Economics, vol. 69, no. 2, pp. 355-373, 2003.

[71] E. F. Fama and J. D. Macbeth, "Risk, return, and equilibrium: empirical tests," Journal of Political Economy, vol. 81, no. 3, pp. 607-636, 1973.

[72] H. Hong and D. A. Sraer, "Speculative betas," The Journal of Finance, vol. 71, no. 5, pp. 2095-2144, 2016.

[73] K. Hou and T. J. Moskowitz, "Market frictions, price delay, and the cross-section of expected returns," Review of Financial Studies, vol. 18, no. 3, pp. 981-1020, 2005.

[74] V. T. Datar, N. Y. Naik, and R. Radcliffe, "Liquidity and stock returns: an alternative test," Journal of Financial Markets, vol. 1, no. 2, pp. 203-219, 1998.

[75] J. N. Carpenter, F. Lu, and R. F. Whitelaw, The Real Value of China's Stock Market, National Bureau of Economic Research, Cambridge, MA, USA, 2014.

[76] F. Jiang, J. Lee, X. Martin, and G. Zhou, "Manager sentiment and stock returns," Journal of Financial Economics, vol. 132, no. 1, pp. 126-149, 2019.

[77] J. A. Ou and S. H. Penman, "Financial statement analysis and the prediction of stock returns," Journal of Accounting and Economics, vol. 11, no. 4, pp. 295-329, 1989.

[78] M. R. Gibbons, S. A. Ross, and J. Shanken, "A test of the efficiency of a given portfolio," Econometrica, vol. 57, no. 5, pp. 1121-1152, 1989. 